\title{
The Annual Bibliography; aims and current changes
}

ici fenist li premiers vers.

Erec

This volume of the Bibliography of the International Arthurian Society (BIAS) marks the end of a long series. Since 1949 the preceeding Bibliographical Bulletin of the International Arthurian Society / Bulletin Bibliographique de la Société Internationale Arthurienne draws, year by year, attention to scholarly works concerned with the matière de Bretagne. The Bibliography is one of the main objectives of the society that was founded after the second Arthurian Congress in Quimper in 1948. In 68 volumes about 40.000 items have been collected by hundreds of bibliographers, merged by 9 editors. Up to volume LXIV it held further material: particular articles, that have been published in JIAS (Journal of the International Arthurian Society) since 2013, as well as a list of officers of the society and a list of members (now online on the society's website at http://www.internationalarthuriansociety.com/).

After all this time Arthurian scholarship is more vivid than ever. Therefore it is our intention to adjust BIAS to the needs and possibilities of our time. The last printed volume lists publications till 2015. Later publications will be published online as an open and free database at $<\mathrm{http}$ ://bias.internationalarthuriansociety.com/> It is the society's aim to digitalise the past volumes and integrate them into the database as soon as funding will be available.

The editor would like to express his gratitude for all help during the publication of this volume. In particular I am grateful for the pleasant collaboration with the staff at De Gruyter. Niklas Kunz did magnificent work to write the database. Simon Jenke and Antonia Krihl assisted with the edition of the data. Ann Howey entered the data for the North American branch. 